\title{
Isli and Tislit: The First Dual Impact Crater Discovered in Morocco
}

\author{
Abderrahmane Ibhi $^{1}$, Hassane Nachit ${ }^{1}$, El Hassan Abia ${ }^{1}$, Ahmed Ait Touchnt ${ }^{2}$, Carmela Vaccaro ${ }^{2}$ \\ ${ }^{1}$ Geoheritage and Geomaterials Laboratory, Faculty of Sciences, University of Ibn Zohr, Agadir, Morocco \\ ${ }^{2}$ Department of Earth Sciences, University of Ferrara, Ferrara, Italy \\ Email: a.ibhi@uiz.ac.ma
}

Received January 7, 2013; revised February 9, 2013; accepted February 17, 2013

Copyright (c) 2013 Abderrahmane Ibhi et al. This is an open access article distributed under the Creative Commons Attribution License, which permits unrestricted use, distribution, and reproduction in any medium, provided the original work is properly cited.

\begin{abstract}
Isli and Tislit, the Moroccan "Romeo and Juliette" according to a popular legend gave their name to a twin lakes in Imilchil. There we show evidences that these two lakes are impact craters. The proof as follow: 1) the fragments of iron meteorites found on both sides of Isli and Tislit lakes belong to the same parent meteorite and siderite type; 2) the sedimentary formations which are almost tabular in the area of the lakes become tilted with a centripetal sloping all around and towards Isli lake; 3) the circular shape of the Tislit lake is similar to that of the Isli lake; 4) the impact breccias found on the south of the Isli lake contain shocked quartz crystals; 5) the radial fractures of high pressure affect some sedimentary beds. All these observations give evidence of the presence of an impact crater due to the fall of meteorites.
\end{abstract}

Keywords: Meteorite; Ataxite; Impact Crater; Shocked Quartz; Impact Breccias; Morocco

\section{Introduction}

More than 183 structures of meteoritical impacts are highlighted on the Earth [1], including only three dual impact craters (doublet structure formed on synchronous impact of twin projectiles) reported worldwide: 1) the astroblemes Clearwater East et Clearwater West which are currently filled by two lakes, near the Hudson Bay (Quebec); 2) Arkenu I and II in Libya; and 3) Wabar in Saudi Arabia [2]. Statistics predicts that impact events producing small craters on Earth occur on decadal to secular time scales $[3,4]$. However, small craters are rare on Earth, due to a combination of atmospheric destruction of small impactors and the relative ease with which smaller craters can be buried by post-impact sediments or destroyed [5].

The impact craters of Isli and Tislit, $32^{\circ} 13^{\prime} \mathrm{N}, 05^{\circ} 33^{\prime} \mathrm{W}$; $32^{\circ} 12^{\prime} \mathrm{N}, 05^{\circ} 38^{\prime} \mathrm{W}$ are respectively, located at $10 \mathrm{~km}$ and $4 \mathrm{~km}$ from the Imilchil village on the Central High Atlas in Morocco at respective altitudes of 2272 meters and 2266 meters (Figure 1). They are spaced apart from each other by $9.4 \mathrm{~km}$. The origin and the date of formation of these two lakes are still unknown today. Surveys undertaken near them and in the surrounding areas lead to believe that they correspond to a dual meteoritical impact crater. We present here the discovery of this new dual impact crater in the Central High Atlas in Morocco. It is interesting, first by its young age, and then its perfect conservation and the geomorphology of the two depressions (Figures 2A and $\mathbf{B}$ ).

\section{Geological Framework of the Isli and Tislit Lakes}

The Isli and Tislit lakes are located in the axial area of the Central High Atlas. This area is formed by sedimentary deposits; their age spreads from the Trias till the Middle Cretaceous [6]. These geological fields were structured during the alpine orogeny in an alternating of narrow anticlinal megastructures of a direction $\mathrm{N} 70$ and of wide synclinal megastructures with a flat bottom and of a same direction.

The two lakes are situated in the center of a synclinal basin; the platform of lakes with continental red strata outcrops attributed to the Middle Jurassic [6,7]. The sides of the basin are formed especially by the liasic limestones [6] which form the rocky crests and cliffs of the Jbel Bab n'Ouayâd toward the north and of the Jbel Msadrid toward the south, where the altitude generally exceeds 2600 meters to culminate at 3059 meters at the East of Tizi n'Taghighacht. The red layers of the lakes platform are formed by the sediments of the shoreline 


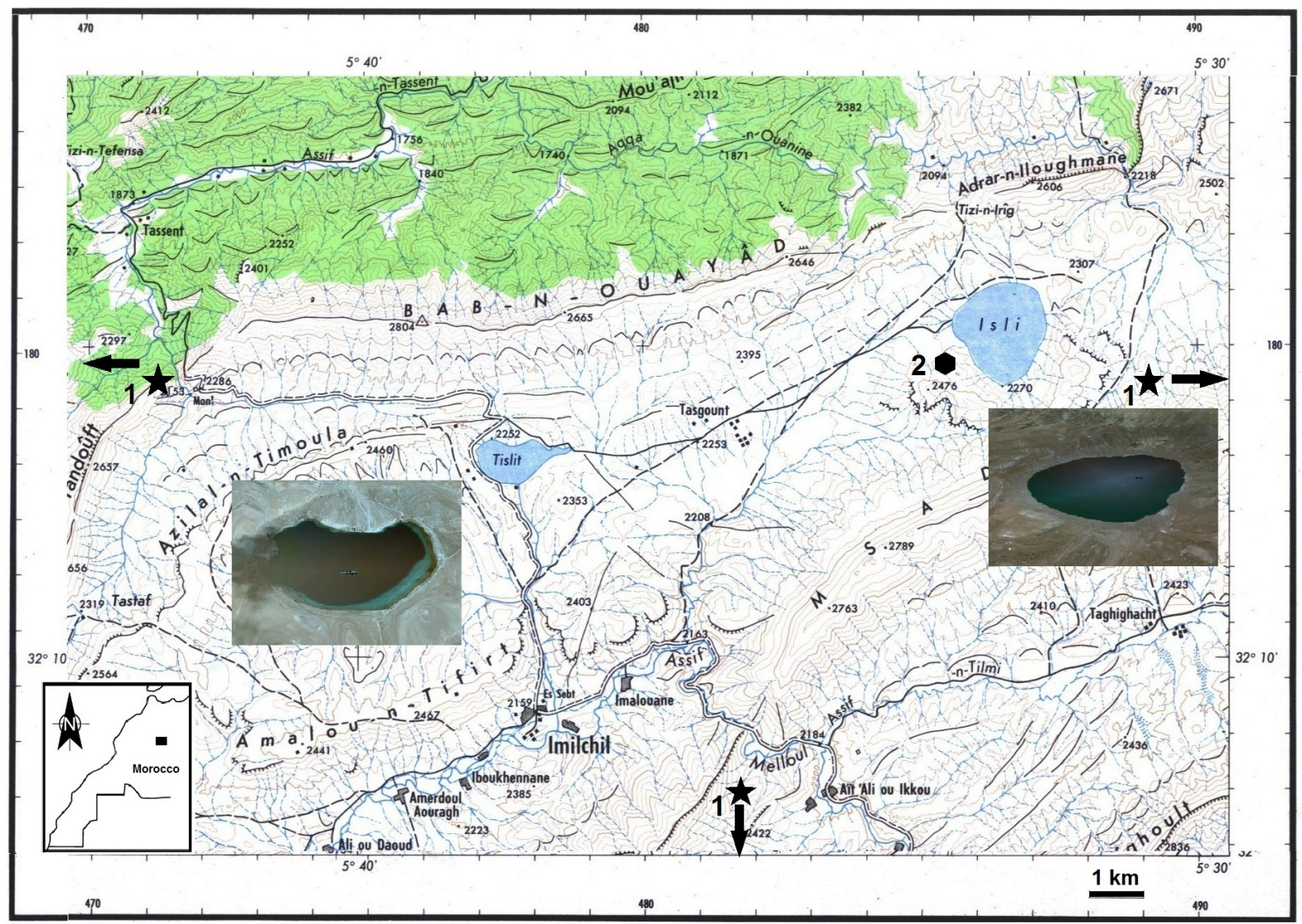

Figure 1. Topographic map showing the location of craters (Google Earth), meteorites (1) and the associated impact breccias (2).
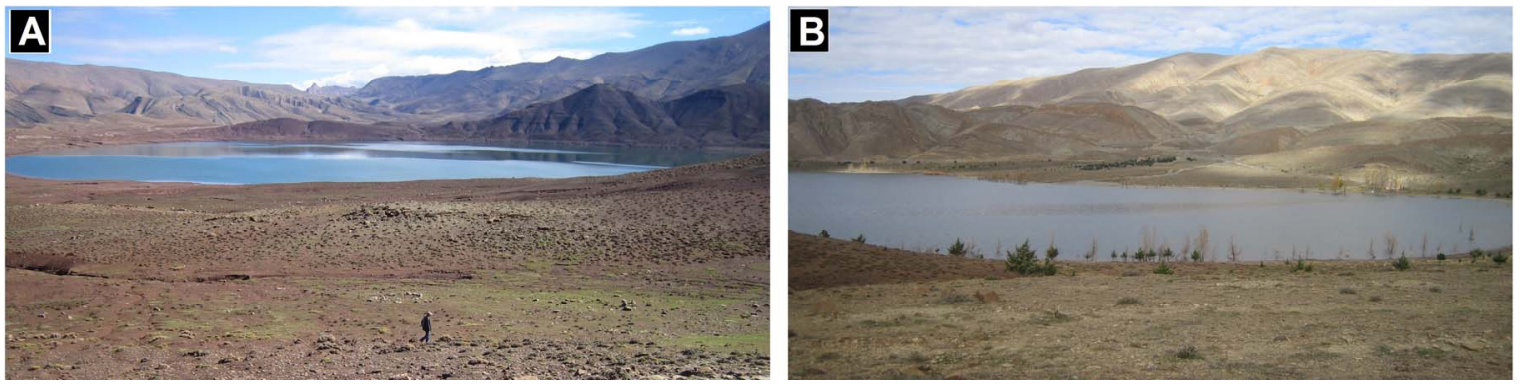

Figure 2. Panorama of the two lakes, A: Isli Lake; B: Tislit Lake.

border and continental sediments especially terrigenous (conglomerates, sandstones, silts and marls) associated to limestone or dolomitic episodes. They're organized into a "trilogy" consisting globally of two coarse detrital units; the formation of Tislit (Middle and Upper Bajocian) and the formation of Isli (Bathonian) framing a clay-evaporate intermediary unit; the formation of Imilchil (Upper Bajocian and Lower Bathonian) [7].

\section{New Observations}

\subsection{Meteorite}

The first fragment of this meteorite was harvested by a nomad in June 2012. Shortly after many pieces of this meteorite came into the Laboratory of the University Ibn Zohr. Immediately a systematic search for meteorites was conducted in an area of $500 \times 500$ meter squares around the impact craters in the areas indicated by the villagers, especially around the villages of Tasrafet and Agoudal. The members of the laboratory harvested many fragments of this meteorite well preserved in the quaternary (Upper Soltanian) layers, dated 40,000 years BP [8]. The collected fragments on the both sides of the both impact craters and those collected on the surrounding plains are of the same nature, thus having fragments produced by a large explosion by the impactor during a 
collision with the soil's surface. Samples weighing $100 \mathrm{~g}$ to more than $9 \mathrm{~kg}$ (Figures $\mathbf{3 A - C}$ ) were harvested at several kilometers from the west to the east of the craters (Figure 1) this shows the force of the explosion or simply the strewn field direction.

The samples found have a rusty appearance, with scales of alteration of several centimeters thick of oxides and iron hydroxide covering the entire outer surfaces thereof, indicating a long residence time in the soil. The polished surfaces don't show the Widmanstatten figures. The meteorite of Imilchil is an Ataxite rich in nickel, it consists mainly of iron mixed with $17.3 \%$ nickel (X-ray fluorescence method in the department of Earth sciences, the University of Ferrara). The scanning electron microscopy revealed the presence of thin diffuse bands of kamacite (around $25 \mu \mathrm{m}$ wide) in a matrix of plessite (Figure 3D) this texture is the evidence of structural deformation due to shock impact. The hardness of the samples measured using a durometer (digital Microhardness Tester FM 700 e) under a load between $10 \mathrm{~g}$ and $2 \mathrm{~kg}$ shows that they have a structural heterogeneity as the micro hardness is 236.8 HV, while the macro hardness is $172.2 \mathrm{HV}$.

\subsection{Impact Craters}

The dual impact craters of Imilchil (Isli and Tislit) affect the jurassic sedimentary formations (red layers). The both craters are practically circular and they have respectively 1500 and 1000 meters in diameter.

The crater Isli is an enough regular bowl with very pronounced slopes; its maximum depth is 95 meters, the seismic profiles obtained reveal that the thickness of sediments filling the lake is 100 meters; the oldest have an age of about 35,000 years [9]. The sedimentary formations that are almost tabular in the platform lakes become inclined with centripetal dips, all around, towards the Isli lake forming thus its watershed. The current shape more or less elongated of the Tislit lake (27 meters deep)

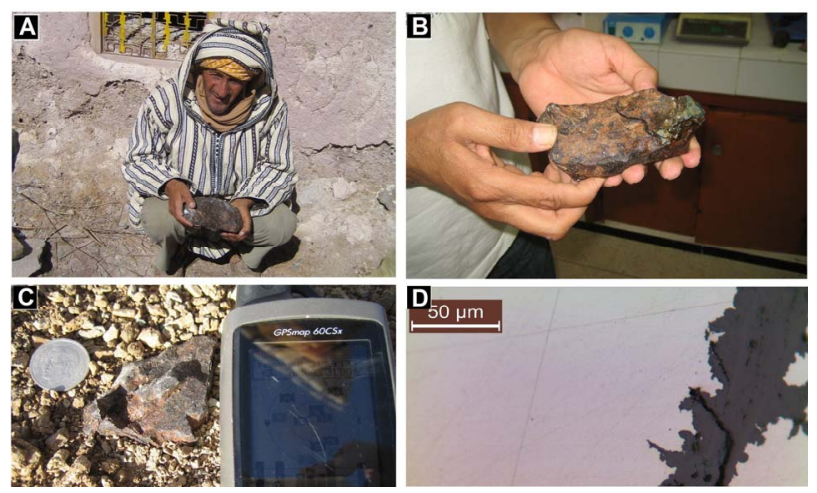

Figure 3. Meteorite fragments of Imilchil. A: Sample of more than $9 \mathrm{~kg}$; B: Sample of more than $1.5 \mathrm{~kg}$; C: Sample of 290 grams on site; D: Band of kamacite in a plessite matrix. is due to the fact that it is provided to the north, with an alluvial fan that alters its circular shape (Figure 2).

Ploymict and monomict breccias were observed at the edges of these craters (Figures 4A and B), they don't form big masses, the erosion was probably erased most. They consist of irregular fragments with millimeter and centimeter sizes, in a carbonate matrix. In the breccias collected on the southern edges of the Isli crater, we noted the presence of several shocked quartz grains in planar structures (FP) $[10,11]$ associated sometimes with rolling extinction (Figure 4B), indicators of shock metamorphism. The most quartz grains have a single family of PFs, but some grains have two families of planar structures. These breccias could be the result of debris ejecta. We could also observe radial fractures (Figures 4C and D) which could have been produced by impacts [12].

\section{Discussion and Conclusions}

Our observations lead to a structural outline of an impact. The fragments of meteorites (around $180 \mathrm{Kg}$ ) found in the area all belong to one and the same parent meteorite called Ataxite. Sedimentary layers are verticalized around the Isli crater; outside the edges of the crater, there is no evidence of vertical layers. This is most likely due to a meteorite fall [13]. Witnesses of impact breccias are still present on the edges of craters, although most of these breccias had been erased by erosion. These breccias contain shocked quartz grains with planar structures indicators of shock metamorphism [5-10].

In conclusion, based on these observations we can confirm that the circular structures of Isli and Tislit discovered in the north of Imilchil (Morocco) were produced by the impact of a small asteroid with more than
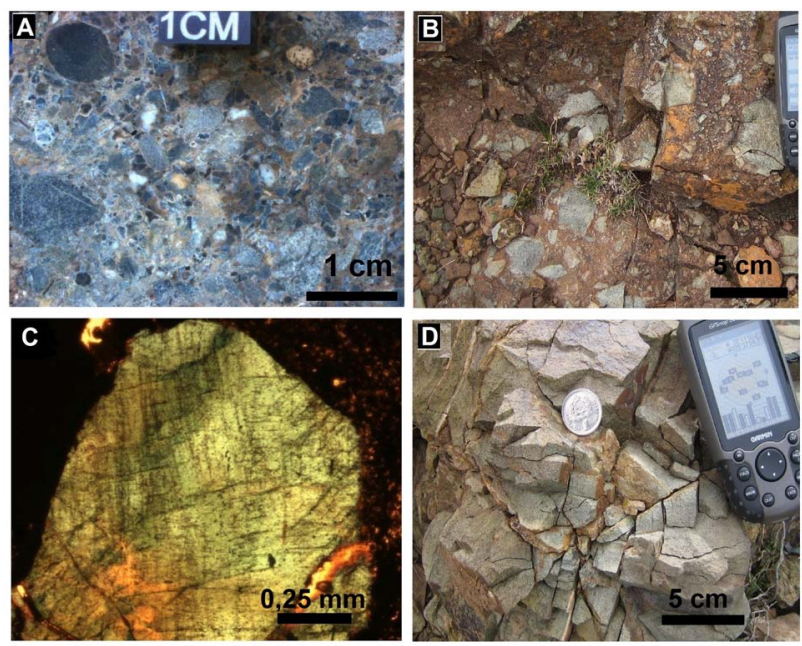

Figure 4. Metamorphism impact figures. A: polymict breccias. B: monomict breccias; C: shocked quartz showing PFs. D: radial fractures. 
100 meters in diameter.

The dual impact crater, oriented east-west, resulted from the fragmentation of a meteorite at its input in the Earth's atmosphere in two pieces which then produced two craters, oriented along the trajectory of the fireball $[14,15]$. This phenomenon has been observed in three double craters identified in the world [2]. According to the state of conservation of the meteorite into the sedimentary layers "Soltanian" and the dating of ancient lake sediments of the Isli lake [9], we can estimate their age limit to 40,000 years.

\section{REFERENCES}

[1] J. Spray, “Earth Impact Database,” 2011. http://www.passc.net/EarthImpactDatabase/index.html

[2] J. N. Salomon and T. Auly, "Impactors and Astroblems: Attempt of Classification and Geographical Approach," Géomorphologie, No. 1, 2010, pp. 3-20.

[3] P. Brown, R. E. Spalding, D. O. ReVelle, E. Tagliaferri and S. P. Worden, "The Flux of Small Near-Earth Objects Colliding with the Earth,” Nature, Vol. 420, No. 6913, 2002, pp. 294-296. doi:10.1038/nature01238

[4] P. A. Bland and N. A. Artemieva, "The Rate of Small Impacts on Earth,” Meteoritics \& Planetary Science, Vol. 41, No. 4, 2006, pp. 607-631. doi:10.1111/j.1945-5100.2006.tb00485.x

[5] R. A. F. Grieve, “The Terrestrial Cratering Record,” In: B. Peucker-Ehrenbrink and B. Schmitz, Ed., Accretion of EXtraterrestrial Matter Throughout Earth's History, SpringerVerlag, New York, 2001, pp. 379-402.

[6] A. Fadile, “Geological Map of Morocco, Imilchil,” Notes et Mémoires du Service Geologique Maroc, Vol. 397, 2003, scale 1:100 000, sheet 1 .

[7] H. Ibouh, "Du Rift Avorté au Bassin sur Décrochement,
Contrôles Tectonique et Sédimentaire Pendant le Jurassique (Haut Atlas Central, Maroc),” Ph.D. Thesis, Cadi Ayyad University, Morocco, 2004.

[8] A. Weisrock and M. Fontugne, "Morphogenèse Eolienne Littorale au Pléistocene Supérieur et à l'Holocène Dans l'Oulja Atlantique Marocaine," Quaternaire, Vol. 3, No. 3-4,1991, pp. 164-175. doi:10.3406/quate.1991.1965

[9] E. Zeroual, "Enregistrements Climatiques Dans les Sédiments de lac Isli (Haut Atlas, Maroc),” Ph.D. Thesis, Cadi Ayyad University, Morocco, 1995.

[10] D. Stöeffler and F. Langenhorst, "Shock Metamorphism of Quartz in Nature and Experiment: I. Basic Observations and Theory," Meteoritics \& Planetary Science, Vol. 29, No. 2, 1994, pp. 155-181. doi:10.1111/j.1945-5100.1994.tb00670.x

[11] R. A. F. Grieve, F. Langenhorst and D. Stöffler, "Shock Metamorphism of Quartz in Nature and Experiment," Meteoritics \& Planetary Science, Vol. 31, No. 1, 1996, pp. 6-35. doi:10.1111/j.1945-5100.1996.tb02049.x

[12] A. Sagy, Z. Reches and J. Fineberg, "Dynamic Fracture by Large Extraterrestrial Impacts as the Origin of Shatter Cones,” Nature, Vol. 418, No. 6895, 2002, pp. 310-313. doi:10.1038/nature00903

[13] J. F. Moyen, “La Structure d'Impact de Vredefort,” In: M J. Van Kranendonk, R. H. Smithies and V. Bennett, Ed., Earth's Oldest Rocks, Elsevier, 2007, pp. 669-698. http://www.academia.edu/1107614/La_structure_dimpact _de_Vredefort

[14] M. R. Dence, “Meteorite Breakup,” Nature, Vol. 289, No 198, pp. 346-351.

[15] B. M. French and C. Koeberl, “The Convincing Identification of Terrestrial Meteorite Impact Structures: What Works, What Doesn't, and Why," Earth-Science Reviews, Vol. 98, 2010, pp. 123-170. doi:10.1016/j.earscirev.2009.10.009 